Doi: HTTPS://DOI.ORG/10.23910/IJEP/2019.6.3.0325

\title{
First Report of Pestalotiopsis clavispora (G.F. Atk.) Steyaert Causing Crown Rot Disease on Strawberry in India
}

\author{
D. A. Bhagariya ${ }^{1}$ and V. P. Prajapati ${ }^{2 *}$
}

${ }^{1}$ Dept. of Plant Pathology, N. M. College of Agriculture, Navsari Agricultural University, Navsari, Gujarat (396 450), India

${ }^{2}$ Dept. of Plant Pathology, ASPEE College of Horticulture and Forestry, Navsari Agricultural University, Navsari, Gujarat (396 450), India

\section{Corresponding Author}

V. P. Prajapati

e-mail: virpathologist@nau.in
Article History

Article ID: IJEP0325

Received in $10^{\text {th }}$ August, 2019

Received in revised form $18^{\text {th }}$ August, 2019

Accepted in final form 26 $6^{\text {th }}$ August, 2019

\section{Abstract}

The crown rot disease was recorded for the first time on strawberry Field from Hill Millet Research Station, Waghai, Gujarat state of India during 2017-2018. The diseased plants showed drying from the edge of the leaves. Dark lesion appears first on leaves and spreads downward to the crown region. The severely infected plant parts i.e., leaves, flowers, stems, fruits and roots are gradually turned into dark black in colour and later on plant had completely dried and resemble the symptoms of crown rot. The fungus was isolated from the diseased plant parts and subsequent re-inoculation of the same to healthy plants and its pathogenicity confirmed which revealed that Pestalotiopsis clavispora (G.F. Atk.) Steyaert is the causal organism. Pathogenicity tests showed that Pestalotiopsis clavispora could infect strawberry, which developed the same symptoms under artificial inoculation conditions to that observed in the field. Further, the fungus was identified based on morphological and cultural characteristics and this is the first report from India showing that Pestalotiopsis clavispora causes crown rot on strawberry.

Keywords: Crown rot, India, Pestalotiopsis clavispora, strawberry

\section{Introduction}

Strawberry (Fragariaxananassa Duch.) is one of the most important soft fruits of world and occupies an important place amongst small fruits. It occupies an area of 395,844 ha with a total production of 9,223,815 MT (FAO, 2017). In India, strawberry cultivation is confined only to hilly tracts of Himachal Pradesh, Uttrakhand, Jammu Kashmir, West Bengal, Haryana, Uttar Pradesh, Punjab, Maharashtra and Karnataka have their own identity for strawberry production occupied an area of 1000ha with a total production of $5000 \mathrm{MT}$ (NHB, 2018). In Gujarat, Dang district is the main area of strawberry cultivation. Many villages having over an area of 23 ha with weekly production of 1,750 kg of fresh strawberry (TOI, 2018). The area under its cultivation has increased considerably in the last 2 years with the awareness among fruit growers and better transport and storage facilities. Diseases are the major constraints in economic production of strawberry. Many pathogen of strawberry have been recorded over the world (Dung et al., 2016). However, crown rot is caused by several pathogens viz., Pestalotiopsis sp. Phytophthora cactorum, Colletotrichum acutatum, C. gloeosporioides and C. fragaria. Among them, Pestalotiopsis spp. causes crown rot that poses a serious threat to the crop inflicting qualitative and quantitative reduction in strawberry production (Dung et al., 2016).

\section{Materials and Methods}

Infected samples which showed typical symptoms of crown rot disease was collected from strawberry field in Hill Millet Research Station, Waghai, Gujarat state of India during 2017-2018. The samples were then taken to the laboratory (Department of Plant pathology, N.M.C.A., Navsari Agricultural University, Navsari) for isolation of causal agent of diseases and further studies.

\subsection{Isolation of pathogens}

Small pieces of diseased tissues along with adjoining healthy tissues were cut and surface sterilized by dipping in $0.1 \% \mathrm{HgCl}_{2}$ solution for 1 minute followed by three subsequent washings with sterilized distilled water and these pieces were then aseptically transferred to sterilized Petri plates containing $20 \mathrm{ml}$ Potato dextrose agar (PDA) medium and incubated at average mean temperature $\left(25 \pm 2{ }^{\circ} \mathrm{C}\right)$. The growth of the fungus developed after $48 \mathrm{hrs}$ of incubation was sub cultured to obtain pure culture by hyphal tip method that was further maintained by frequent sub-culturing and the isolate was used for further studies. 


\subsection{Pathogenicity test}

Pathogenicity test was carried out using a spraying of spore suspension method. Three plastic pots were filled with autoclaved soil and strawberry runners of plant were sown in each of the pots. The foliar inoculation was done on one month old plant with spore suspension $\left(1 \times 10^{7}\right.$ spores $\left.\mathrm{ml}^{-1}\right)$ was prepared from 7 days old culture of Pestalotiopsis spp. by homogenization of culture in sterile distilled water. The pots were watered to soil saturation in the morning and the inoculation carried out in the evening time. The healthy strawberry leaves were washed with sterilized distilled water before inoculation. Suitable controls with only sterilized distilled water spray were maintained. All the leaves were then covered with moist cotton swab kept under moist polythene bags to maintain humidity.

The observations with regards to infection and symptoms development were recorded regularly. The fungus was reisolated from the inoculated diseased leaves displaying crown rot symptoms and the morphological and cultural characters were compared with those of Pestalotiopsis spp., which was originally isolated from diseased strawberry leaves and crown.

\subsection{Identification}

Identification of the pathogen was done by using cultural and
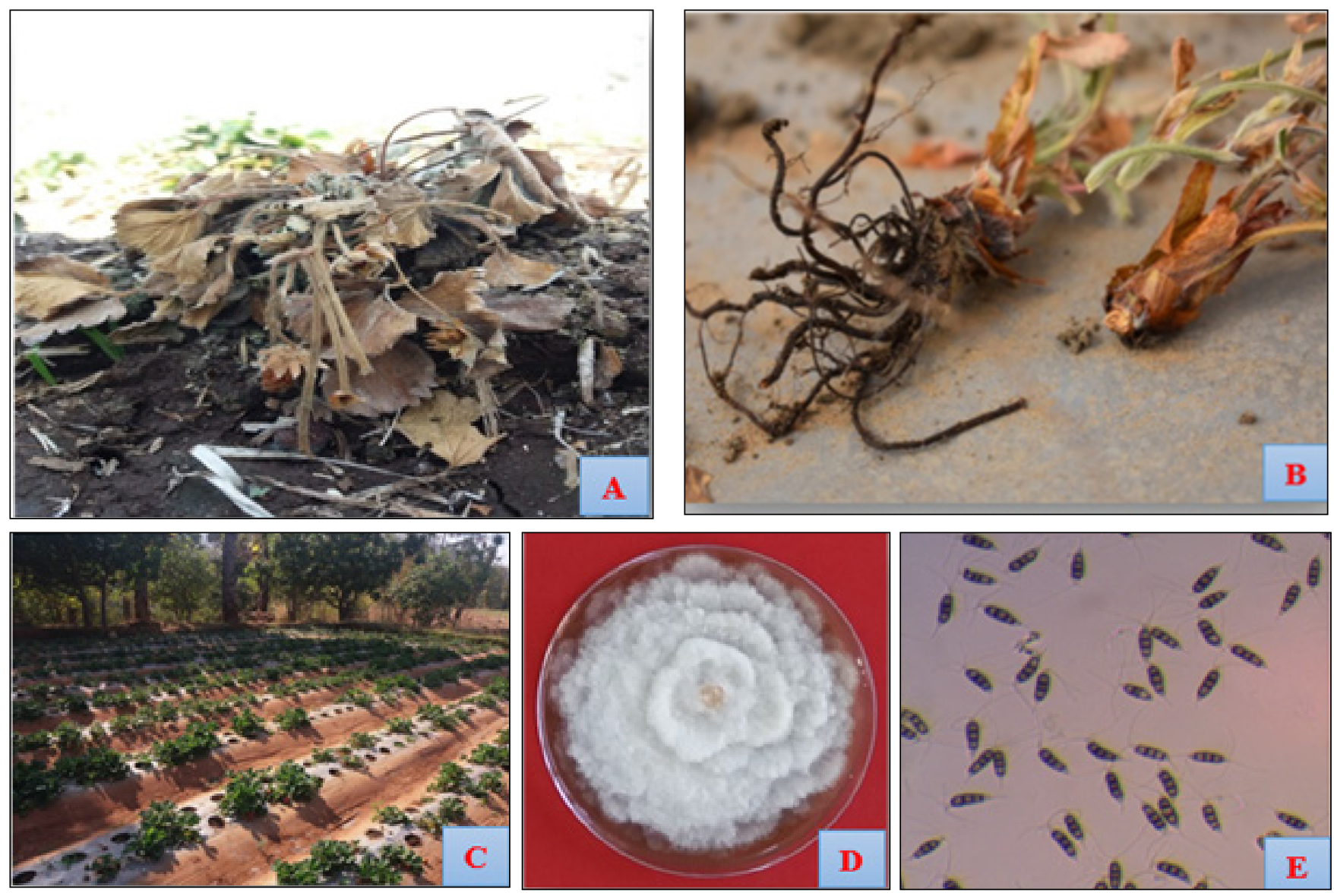

Figure 1: Diseased symptoms in the field (A, C), Diseased on the plant root and crown (B), Morphological features of Pestalotiopsis clavispora 7 days post inoculation (D) on PDA medium and conidia of Pestalotiopsis clavispora (E)

$\varnothing$ 
Waghai, Gujarat state of India during 2017-2018 and brought to the collage laboratory, which were subjected to microscopic examination and then tissue isolation was done from infected plants, which yielded the pure culture of Pestalotiopsis sp. The culture was further purified by frequent sub culturing by hyphal tip method and maintained on Potato dextrose agar (PDA) slants or Petri dishes containing PDA for further investigation.

\subsection{Pathogenicity test}

After inoculation on plants, symptoms appeared at first as blightening of leaves from edges. The disease then spread from top to the bottom part of the plant and then spread down to crown region. Leaves and stem became dried and blacken in color were observed after 8 days of inoculation While, crown rot and fruit rot symptoms were observed after 19 and 10 days after inoculation, respectively. Spraying sterilized distilled water on uninjured leaf surface produced no disease symptoms on strawberry plant.

$\mathrm{Re}$ isolation from infected parts of strawberry yielded Pestalotiopsis sp. which proved the Koch's postulate that the disease symptoms were caused by the same fungus that was originally isolated. Similar result was found as previously reported by Dung et al. (2016).

\subsection{Conidial characters}

All cells had five celled conidia of which apical and basal cells were hyaline and three median cells ranged from light to dark brown. Conidia varied from 23.45 to $25.82 \mu \mathrm{m}$ mean length and 6.74 to $7.30 \mu \mathrm{m}$ mean width with three apical appendages and one basal appendages. Fungal colonies on PDA grew to 75-85 mm diameter in one week at room temperature $(25 \pm 2$ $\left.{ }^{\circ} \mathrm{C}\right)$ with grayish to white color and cottony, edge undulate, circular growth appearance on PDA medium.

\subsection{Identification of the pathogen}

The fungal isolation was obtained by tissue isolation technique from the infected leaves and crown region of strawberry. The morphological and cultural characters of the isolate grown on PDA were studied and compared with those mentioned in the literature. Pure culture of Pestalotiopsis sp. was sent to Indian Type Culture Collection (ITCC), Division of Plant Pathology, ICAR-Indian Agricultural Research Institute, New Delhi, where it was identified as Pestalotiopsis clavispora (G.F. Atk.) Steyaert (ITCC No.-10818.18). Thus, the pathogen under study was identified and confirmed as $P$. clavispora and this is the first report of $P$. clavispora causing crown rot on strawberry plants in India.

\section{Conclusion}

The fungus was isolated from the diseased plant parts and subsequent re-inoculation of the same to healthy plants and its pathogenicity confirmed which revealed that Pestalotiopsis clavispora (G.F. Atk.) Steyaert is the causal organism. Pathogenicity tests showed that Pestalotiopsis clavispora could infect strawberry, which developed the same symptoms under artificial inoculation conditions to that observed in the field. This is the first report from India showing that Pestalotiopsis clavispora causes crown rot on strawberry.

\section{References}

NHB., 2018. National Horticulture Board, India. Available from http://nhb.gov.in/statistics/State_Level/2017-18.

TOI., 2018. Quality strawberries help Dangs farmers reap riches. Available from https://timesofindia.indiatimes. com/city/surat/quality-strawberries-help-dang-farmersreap-riches/articleshow/62795605.cms.

Ara, T., Monzur, S., Saand, M.A., Islam, R., Alam, S., Hossain, M., 2017. The first report of Pestalotiopsis sp. causing crown rot disease on strawberry (Fragaria $\times$ ananassa Duch.) in Bangladesh and evaluation of fungicide activity. International Journal of Biosciences 11(4), 350-358.

Chamorro, M., Aguado, A., Santos, B.D., 2016. First report of root and crown rot caused by Pestalotiopsis clavispora (Neopestalotiopsis clavispora) on strawberry in Spain. Plant Disease 100(7), 1495.

Dung, L., Dienb, N.T., Daic, P.H., Tuana, P.N., 2016. The first report of Pestalotiopsis sp. causing crown rot disease on strawberries in Dalat. Dalat University Journal of Science, 6(3), 364-376. 